$$
\text { Mary Ann Liebert, Inc. publishers }
$$

\title{
Is Periconceptional Substance Use Associated with Unintended Pregnancy?
}

\author{
Lisbet S. Lundsberg, ${ }^{*}$ Meredith J. Pensak, and Aileen M. Gariepy
}

\begin{abstract}
Background: To evaluate the relationship between periconceptional (period before and/or after conception) substance use and unfavorable pregnancy contexts, including unintended pregnancy.

Materials and Methods: This is a cross-sectional analysis of English- or Spanish-speaking women aged 16-44 years with pregnancies $<24$ weeks' gestation presenting to pregnancy testing clinics and enrolled between June 2014 and June 2015. Participants self-reported periconceptional substance use (tobacco, alcohol, marijuana, and other illicit substances during the 3 months before enrollment), and pregnancy "contexts," including pregnancy intention, wantedness, planning, timing, desirability, and happiness. Multivariable logistic regression was performed adjusting for potential confounding variables.

Results: We enrolled 123 women, averaging $27 \pm 6$ years, and mean gestational age $7.5 \pm 3.0$ weeks. Most participants were black, non-Hispanic (37\%), or Hispanic (46\%), and chose to complete the study in English (69\%). Sixty-five percent participants reported use of one or more substances during prior 3 months: alcohol (54\%), tobacco (31\%), and marijuana (21\%). In multivariate analysis, periconceptional alcohol use was associated with increased odds of unintended or ambivalent pregnancy and unwanted or mixed feelings regarding pregnancy (odds ratios $[\mathrm{OR}]=3.29,95 \%$ confidence interval $[\mathrm{Cl}] 1.08-10.08$ and $\mathrm{OR}=2.81,95 \% \mathrm{Cl} 1.07-7.36$, respectively). Weekly or daily tobacco use was associated with unhappiness about pregnancy $(\mathrm{OR}=7.56,95 \% \mathrm{Cl} 1.65-$ 34.51) and undesired or unsure pregnancy ( $\mathrm{OR}=4.00,95 \% \mathrm{Cl} 1.14-14.06)$.

Conclusions: Periconceptional alcohol or tobacco use demonstrates increased odds of specific unfavorable pregnancy contexts, including pregnancy described as undesired, unintended, unwanted, and unhappiness with pregnancy. Primary prevention of periconceptional substance use and the negative effects of alcohol and tobacco may be improved by increasing contraception access for women at risk for unfavorable pregnancy contexts.
\end{abstract}

Keywords: alcohol; pregnancy; tobacco; unintended pregnancy; unplanned pregnancy

\section{Introduction}

In efforts to address adverse maternal and neonatal outcomes associated with substance use during pregnancy, organizations including the American College of Obstetricians and Gynecologists, Centers for Disease Control and Prevention, the Royal College of Obstetricians and Gynaecologists, and the World Health Organization have recognized the importance of addressing substance use as an important component of preconception care, ${ }^{1-4}$ including recommendations that pregnant women and women who may become pregnant abstain from any use of tobacco, alcohol, and other illicit substances.

However, focusing on preconception care in this way may be insufficient as it assumes that women have control over their reproductive lives, that contraception never fails, that all pregnancies are planned, and that such assumptions are inherently flawed. ${ }^{5,6}$ For example, purposeful abstinence regarding tobacco, alcohol,

Department of Obstetrics, Gynecology and Reproductive Sciences, Yale University School of Medicine, New Haven, Connecticut.

*Address correspondence to: Lisbet S. Lundsberg, PhD, Department of Obstetrics, Gynecology and Reproductive Sciences, Yale University School of Medicine, 310 Cedar Street, CB 337, New Haven, CT 06510, E-mail: lisbet.lundsberg@yale.edu

(c) Lisbet S. Lundsberg et al. 2020; Published by Mary Ann Liebert, Inc. This Open Access article is distributed under the terms of the Creative Commons License (http://creativecommons.org/licenses/by/4.0), which permits unrestricted use, distribution, and reproduction in any medium, provided the original work is properly cited. 
and illicit substance use before pregnancy is challenging when an estimated $45 \%$ of pregnancies in the United States ${ }^{7}$ and $44 \%$ of all pregnancies worldwide are unintended. ${ }^{8}$

Indeed, previous research has demonstrated associations between periconceptional (period before and/or after conception) substance use and unintended pregnancy, ${ }^{9-11}$ and pregnancy planning and timing. ${ }^{12}$ However, methodological weaknesses include retrospective assessment of substance use and/or pregnancy intention ${ }^{11,13-16}$ and lack of robust adjustment for confounders. ${ }^{10}$ Notably, studies frequently include live births only, thus excluding women with miscarriages or induced abortion. ${ }^{11,13,15,16}$ In addition to these methodologic limitations, previous studies have often narrowly focused on pregnancy intention, ${ }^{9-11,14,16}$ which is criticized for being overly simplistic ${ }^{5,17-20}$ as it may exclude other important pregnancy contexts including pregnancy wantedness, timing, desirability, and happiness with pregnancy news. ${ }^{19}$

Given over one-fifth of U.S. reproductive-aged women use tobacco and $\sim 54 \%-55 \%$ consume alcohol, ${ }^{21,22}$ periconception substance exposure may be prevalent among women with unwanted, poorly timed, undesired, or unhappy pregnancies. Including data on women with miscarriage and induced abortion, evaluating additional pregnancy contexts, and adjusting for confounders may improve understanding of the relationship between substance use and unfavorable pregnancy contexts beyond intention only and allow for innovative public health interventions.

Improved understanding may be especially relevant for addressing the potential negative effects of alcohol and tobacco given the overall prevalence of substance use in reproductive-aged women. For example, if women with periconceptional alcohol use are more likely to have pregnancies that are unintended, unwanted, unplanned, poorly timed, undesired, and/or unhappy, then primary prevention for periconceptional substance use may be improved by increasing contraception access for women at risk of these unfavorable pregnancy contexts.

We sought to examine the relationship between periconceptional tobacco, alcohol, or illicit drug use and discrete patient-centered pregnancy contexts, including intention, wantedness, planning, timing, desirability, and happiness. ${ }^{19}$ We hypothesized that women using substances in the periconceptional period would be more likely to report unfavorable or ambivalent pregnancy context (e.g., unwanted or mixed feelings about pregnancy). Assessment of periconceptional substance use and perspectives of pregnancy context may inform efforts to improve effective contraception access and use among women at risk of unfavorable pregnancy contexts.

\section{Materials and Methods}

Study setting and design

We recruited women presenting for pregnancy testing at two clinical sites in New Haven, CT, from June 2014 to June 2015. A total of 225 women were approached by research staff regarding study participation. Women were eligible if they were 15-44 years of age, pregnant at $<24$ completed weeks gestational age, English or Spanish speaking, and completed study enrollment within 1 week of their clinic pregnancy test. However, no women under age 16 years were enrolled into the study. Recruitment and enrollment specifics have been previously published. ${ }^{23}$

Overall, 123 individuals were eligible, enrolled, and comprise our final sample for this study. We collected enrollment data in person using self-administered paper questionnaires, including comprehensive sociodemographic and maternal characteristics, medical conditions, and reproductive history.

\section{Measures of periconceptional substance use}

Participants were asked about frequency of substance use during the 3 months before enrollment. Measures were obtained for tobacco use (including cigarettes, chewing tobacco, and cigars), alcohol consumption (wine, beer, and liquor), and marijuana use (pot and hash). In addition, use of cocaine, amphetamine-type stimulants, inhalants, sedatives or sleeping pills, and opioids was ascertained. Participants were asked how frequently they used each substance "in the past 3 months," with response options including "never, once/twice, monthly, weekly, or daily." These categories were collapsed and analyzed as three-level categorical variables of never, once/twice or monthly, and weekly or daily.

Owing to the limited number of women indicating use of other illicit substances (cocaine, inhalants, sedatives, and opioids), we analyzed dichotomous measures of illicit substance use (other substance use). Previous research has identified smoking and alcohol use to be related, with efforts to address these preconception behaviors jointly. ${ }^{24}$ Therefore, we created a summary four-level construct of alcohol and tobacco with mutually exclusive categories of use: neither tobacco or alcohol, tobacco only, alcohol only, and both tobacco and alcohol. 


\section{Measures of pregnancy context}

We assessed pregnancy context at enrollment, ${ }^{19}$ including "prepregnancy perceptions" of pregnancy intention, whether pregnancy was wanted, and pregnancy planning; planning was assessed using the six-item London Measure of Unplanned Pregnancy (LMUP) ${ }^{25}$ Context measures also included assessments of postconception perspectives: pregnancy timing, whether pregnancy was desired, and happiness with pregnancy news. Questions regarding pregnancy timing, intention, and wantedness come from the LMUP.

Pregnancy context was collected as three-level response measures and analyzed as two-level categorical outcome measures, with unfavorable (e.g., "wrong time") or ambivalent/neutral (e.g., "okay but not quite right time") context combined and compared with favorable (e.g., "right time") context; see Appendix Table A1. An additional component of the six-item LMUP ascertained behaviors "in preparation for becoming pregnant." ${ }^{25}$ Discrete response options included whether they were taking folic acid, or ate more healthily. Responses are presented as descriptive variables but not included in multivariable modeling as they are components of planning outcome measure.

\section{Potential confounding variables}

At enrollment, we collected sociodemographic information including age, race-ethnicity, education, employment, and relationship status. We assessed reproductive history including parity, previous miscarriage, and previous abortion. We asked participants whether they had ever been diagnosed with a chronic medical condition (e.g., diabetes and thyroid problem), depression, or anxiety. Gestational age was ascertained using information from self-reported last menstrual period at time of enrollment.

\section{Statistical analysis}

Descriptive and bivariate analyses were used to evaluate the association between substance use and pregnancy context, including chi-square and Fisher's exact tests where appropriate. Logistic regression modeling was performed to generate odds ratios (OR) and 95\% confidence intervals (CIs) for the association between substance use and pregnancy contexts. Multivariable regression modeling was performed adjusting for potential confounding variables using backwards selection at $\alpha=0.10$. For each multivariable model, the specific substance use measure was included as well as potential confounding variables and/or independent risk factors to model the outcome of unfavorable pregnancy context (e.g., wrong time/not quite right time).

Statistical analysis was performed using SAS 9.4 (SAS Institute, Cary, NC). The Yale University Human Research Protection Program and participating sites reviewed and provided approval for the study protocol. All study participants provided written consent before enrollment.

\section{Results}

Mean age of participants was $27( \pm 6)$ years and average gestational age at enrollment was $7.5( \pm 3)$ weeks (Table 1). ${ }^{23}$ Most women were black, non-Hispanic (37\%), or Hispanic (46\%), parous (73\%), and single or living with a partner (72\%). Sixty-nine percent chose to complete the study in English and the remaining in Spanish (31\%). Thirty-nine percent reported a previous miscarriage and 38\% reported a previous abortion.

Table 1. Participant Demographic Characteristics $(N=123)$

\begin{tabular}{|c|c|}
\hline Characteristic & $n(\%)$ \\
\hline \multicolumn{2}{|l|}{ Gestational age at enrollment } \\
\hline$<12$ Completed weeks & $114(94.2)$ \\
\hline$\geq 12$ Completed weeks & $7(5.8)$ \\
\hline Mean gestational age in weeks (SD) & $7.5( \pm 3.0)$ \\
\hline \multicolumn{2}{|l|}{ Language study completed } \\
\hline English & $85(69.1)$ \\
\hline Spanish & 38 (30.9) \\
\hline \multicolumn{2}{|l|}{ Age } \\
\hline$<25$ & $59(48.4)$ \\
\hline$\geq 25$ & $63(51.6)$ \\
\hline Mean age in years (SD) & $26.7( \pm 6.3)$ \\
\hline Range (years) & $16-44$ \\
\hline \multicolumn{2}{|l|}{ Race-ethnicity } \\
\hline Black, non-Hispanic & $45(36.9)$ \\
\hline White, non-Hispanic & $13(10.7)$ \\
\hline Hispanic & $56(45.9)$ \\
\hline Multiracial, other & $8(6.6)$ \\
\hline \multicolumn{2}{|l|}{ Education } \\
\hline 12 Years/General Education Diploma or less & $77(63.1)$ \\
\hline Some college, college degree & $45(36.9)$ \\
\hline \multicolumn{2}{|l|}{ Employment } \\
\hline Unemployed/homemaker & $68(55.7)$ \\
\hline Full time/part time & $54(44.3)$ \\
\hline \multicolumn{2}{|l|}{ Relationship status } \\
\hline Single & $49(40.1)$ \\
\hline Married & $18(14.8)$ \\
\hline Living with partner, not married & $39(32.0)$ \\
\hline Separated, divorced, widowed & $16(13.1)$ \\
\hline Chronic medical problem & $22(17.9)$ \\
\hline Ever diagnosed with depression & $26(21.1)$ \\
\hline Ever diagnosed with anxiety & $24(19.5)$ \\
\hline \multicolumn{2}{|l|}{ Parity } \\
\hline 0 & $33(27.1)$ \\
\hline 1 & 45 (36.9) \\
\hline $2+$ & $44(36.1)$ \\
\hline Previous miscarriage & $45(38.8)$ \\
\hline Previous abortion & $44(37.9)$ \\
\hline Took folic acid in preparation for pregnancy & $10(8.1)$ \\
\hline Ate more healthily in preparation for pregnancy & $23(18.7)$ \\
\hline
\end{tabular}

Numbers may not add to $N=123$ due to missing observations. 
Eighteen percent of women reported a history of a chronic medical condition (e.g., asthma, diabetes, hypertension, and high cholesterol), $21 \%$ reported ever being diagnosed with depression, and $20 \%$ reported ever being diagnosed with anxiety. Only $8 \%$ of women reported taking folic acid and 19\% reported eating healthier in preparation for pregnancy.

Most women (65\%) reported periconceptional substance exposure from any source during the 3 months before enrollment (data not shown). Table 2 presents alcohol was the most common substance used (54\%), followed by tobacco (31\%) and marijuana (21\%). Stimulant or sedative use (4.9\%), and opioid (1.6\%), cocaine $(0.8 \%)$, or inhalant use $(0.8 \%)$ were infrequent among the study sample (individual substance use data not shown). Although most participants described their pregnancy as desired (60\%) and happy with pregnancy news (72\%), the majority reported pregnancy as unfavorable, including unintended or unsure (67\%), unwanted or mixed feelings (62\%), unplanned or ambivalent $(71 \%)$, and occurring at the wrong or not right time (57\%).

Bivariate analysis demonstrates periconceptional tobacco use was associated with pregnancy desirability $(p=0.02)$. Periconceptional alcohol use was associated with measures of pregnancy intention, wantedness, and happiness $(p<0.05)$; other drug use (including stimulants, inhalants, and opioids) was associated with unfavorable or ambivalent pregnancy contexts $(p<0.05)$, except for pregnancy happiness.

Unadjusted models demonstrate increased odds of unfavorable pregnancy context with specific substance use during the periconceptional period (Table 3). Participants reporting weekly or daily tobacco use were more likely to describe pregnancy as undesired or unsure, and unhappy or neutral compared with women not using tobacco. Alcohol use once/twice or monthly was associated with unfavorable pregnancy contexts including wrong or not quite right timing, unwanted or mixed feelings, unintended or changing intentions, and unplanned or ambivalent compared with no alcohol use.

Women with combined tobacco and alcohol use demonstrated increased odds of describing pregnancy as unfavorable with respect to intention, wantedness, timing, and desire for pregnancy compared with women using neither alcohol nor tobacco. Women reporting cannabis use once/twice or monthly were more likely to report the pregnancy as undesired or unsure and unhappy or neutral feelings about the preg- nancy than those with nonuse. Other substance use (stimulants, inhalants, sedatives, and opioids) was associated with unwanted or mixed feelings and undesired or unsure compared with nonuse.

In multivariable analysis (Table 4), weekly or daily tobacco use was associated with undesired or ambivalent pregnancy $(\mathrm{OR}=4.00,95 \% \mathrm{CI} 1.14-14.06)$ and unhappiness or neutrality about the pregnancy $(\mathrm{OR}=7.56$, 95\% CI 1.65-34.51). Women who reported once/twice or monthly alcohol use were more likely to report unintended or changing intentions regarding pregnancy $(\mathrm{OR}=3.29,95 \%$ CI 1.08-10.08), unwanted or having mixed feelings regarding pregnancy $(\mathrm{OR}=2.81,95 \%$ CI 1.07-7.36), and were less likely to report feeling unhappy or neutral regarding pregnancy $(\mathrm{OR}=0.16,95 \%$ CI 0.03-0.76) than women who did not drink.

Use of alcohol (not with tobacco use) demonstrated reduced odds for undesired or ambivalent, and unhappy or neutral feelings compared with those with neither alcohol nor tobacco use. No significant association was observed between cannabis use or other substance use and unfavorable pregnancy contexts.

\section{Discussion}

Among a diverse cohort of women enrolled in early pregnancy, periconceptional substance use demonstrated increased odds of unfavorable pregnancy contexts. Tobacco use was associated with increased odds of undesired or unsure pregnancy, and unhappiness or neutrality regarding the pregnancy, but was not associated with pregnancy intention, wantedness, planning, or timing. Alcohol use was associated with increased odds of pregnancy described as unintended or intentions changing, unwanted or mixed feelings, and unplanned or ambivalent, but was not associated with pregnancy planning, or desirability. Marijuana use did not show a significant association with any pregnancy context, and periconceptional substance use was not associated with pregnancies that were unplanned or ambivalent, or that occurred at the wrong or not quite right time.

Previous research has demonstrated an increased risk of alcohol use and unintended pregnancy, ${ }^{11,26,27}$ although alcohol exposure is often assessed as patterns of heavy or binge drinking. ${ }^{1,27}$ Studies have also reported an association between preconception and prenatal smoking and unwanted pregnancy ${ }^{15,28}$; however, we observed no association with tobacco smoking and unwanted pregnancy but rather an increased likelihood of undesired or ambivalent pregnancy, and 


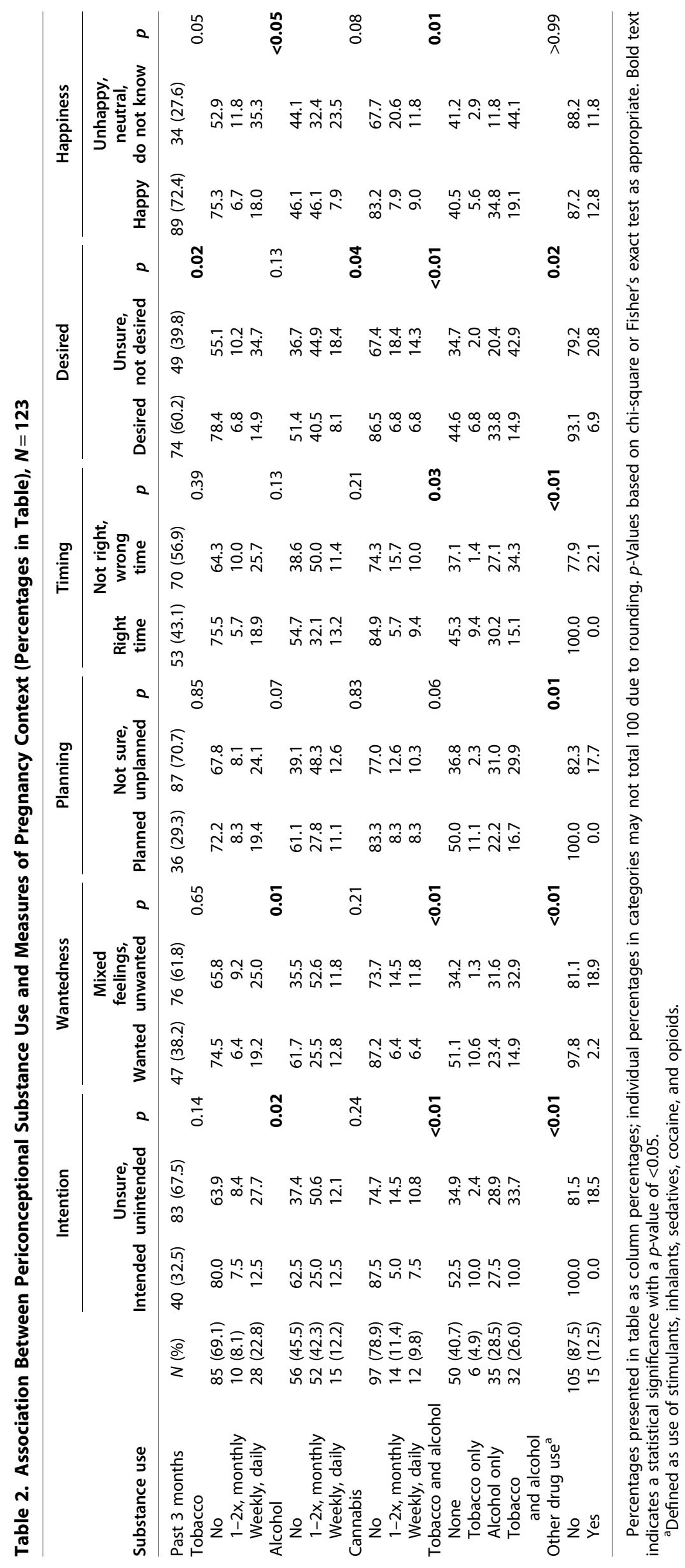


Table 3. Unadjusted Odds Ratio Estimates for Periconceptional Substance Use and Measures of Pregnancy Context

\begin{tabular}{|c|c|c|c|c|c|c|c|c|c|c|c|c|}
\hline \multirow[b]{2}{*}{ Substance } & \multicolumn{2}{|c|}{$\begin{array}{l}\text { Unintended or } \\
\text { intentions changing }\end{array}$} & \multicolumn{2}{|c|}{$\begin{array}{l}\text { Unwanted or } \\
\text { mixed feelings }\end{array}$} & \multicolumn{2}{|c|}{$\begin{array}{c}\text { Unplanned } \\
\text { or ambivalent }\end{array}$} & \multicolumn{2}{|c|}{$\begin{array}{l}\text { Wrong or not } \\
\text { quite right time }\end{array}$} & \multicolumn{2}{|c|}{$\begin{array}{l}\text { Not desired } \\
\text { or unsure }\end{array}$} & \multicolumn{2}{|c|}{$\begin{array}{c}\text { Unhappy, very } \\
\text { unhappy, or neutral }\end{array}$} \\
\hline & OR & $95 \% \mathrm{Cl}$ & OR & $95 \% \mathrm{Cl}$ & OR & $95 \% \mathrm{Cl}$ & OR & $95 \% \mathrm{Cl}$ & OR & $95 \% \mathrm{Cl}$ & OR & $95 \% \mathrm{Cl}$ \\
\hline \multicolumn{13}{|l|}{ Tobacco } \\
\hline Never & Ref & & Ref & & Ref & & Ref & & Ref & & Ref & \\
\hline Once/twice or monthly & 1.41 & $0.34-5.84$ & 1.63 & $0.40-6.76$ & 1.03 & $0.25-4.29$ & 2.07 & $0.50-8.56$ & 2.15 & $0.57-8.05$ & 2.48 & $0.63-9.75$ \\
\hline Weekly or daily & 2.78 & $0.96-8.03$ & 1.48 & $0.60-3.65$ & 1.32 & $0.50-3.49$ & 1.60 & $0.66-3.87$ & 3.32 & 1.37-8.05 & 2.79 & $1.12-6.95$ \\
\hline \multicolumn{13}{|l|}{ Alcohol } \\
\hline Never & Ref & & Ref & & Ref & & Ref & & Ref & & Ref & \\
\hline Once/twice or monthly & 3.39 & $1.42-8.07$ & 3.58 & $1.56-8.22$ & 2.72 & $1.13-6.51$ & 2.21 & $1.10-4.83$ & 1.55 & $0.71-3.40$ & 0.73 & $0.30-1.79$ \\
\hline Weekly or daily & 1.61 & $0.49-5.33$ & 1.61 & $0.51-5.13$ & 1.78 & $0.50-6.30$ & 1.23 & $0.39-3.85$ & 3.17 & $0.98-10.26$ & 3.12 & $0.97-10.11$ \\
\hline \multicolumn{13}{|l|}{ Cannabis } \\
\hline None & Ref & & Ref & & Ref & & Ref & & Ref & & Ref & \\
\hline Once/twice or monthly & 3.39 & $0.72-16.0$ & 2.69 & $0.70-10.24$ & 1.64 & $0.43-6.31$ & 3.17 & $0.83-12.09$ & 3.49 & $1.08-11.26$ & 3.22 & $1.02-10.14$ \\
\hline Weekly or daily & 1.69 & $0.43-6.67$ & 2.20 & $0.56-8.62$ & 1.34 & $0.34-5.32$ & 1.21 & $0.36-4.08$ & 2.72 & $0.80-9.22$ & 1.61 & $0.44-5.83$ \\
\hline \multicolumn{13}{|l|}{ Tobacco and alcohol } \\
\hline None & Ref & & Ref & & Ref & & Ref & & Ref & & Ref & \\
\hline Tobacco only & 0.36 & $0.06-2.16$ & 0.19 & $0.02-1.70$ & 0.28 & $0.05-1.69$ & 0.19 & $0.02-1.70$ & 0.39 & $0.04-3.59$ & 0.51 & $0.06-4.80$ \\
\hline Alcohol only & 1.58 & $0.64-3.92$ & 2.01 & $0.82-4.97$ & 1.90 & $0.71-5.05$ & 1.10 & $0.46-2.61$ & 0.78 & $0.30-1.98$ & 0.33 & $0.10-1.11$ \\
\hline Tobacco and alcohol & 5.07 & $1.54-16.63$ & 3.30 & $1.21-9.01$ & 2.44 & $0.85-7.03$ & 2.77 & $1.05-7.33$ & 3.71 & $1.46-9.44$ & 2.27 & $0.90-5.75$ \\
\hline \multicolumn{13}{|l|}{ Other drug use $\mathrm{a}^{\mathrm{a}}$} \\
\hline No & Ref & & Ref & & Ref & & Ref & & Ref & & Ref & \\
\hline Yes & NAC & & 10.50 & 1.33-82.79 & NAC & & NAC & & 3.53 & $1.12-11.08$ & 0.91 & $0.27-3.08$ \\
\hline
\end{tabular}

Bold text indicates a statistical significance with a $p$-value of $<0.05$.

${ }^{a}$ Defined as use of stimulants, inhalants, sedatives, cocaine, opioids.

$\mathrm{Cl}$, confidence interval; NAC, not able to calculate; OR, odds ratios.

Table 4. Adjusted Odds Ratio Estimates for Periconceptional Substance Use and Measures of Pregnancy Context

\begin{tabular}{|c|c|c|c|c|c|c|c|c|c|c|c|c|}
\hline \multirow[b]{2}{*}{ Substance } & \multicolumn{2}{|c|}{$\begin{array}{l}\text { Unintended or } \\
\text { intentions changing }\end{array}$} & \multicolumn{2}{|c|}{$\begin{array}{l}\text { Unwanted or } \\
\text { mixed feelings }\end{array}$} & \multicolumn{2}{|c|}{$\begin{array}{l}\text { Ambivalent } \\
\text { or unplanned }\end{array}$} & \multicolumn{2}{|c|}{$\begin{array}{l}\text { Wrong or not } \\
\text { quite right time }\end{array}$} & \multicolumn{2}{|c|}{$\begin{array}{l}\text { Not desired } \\
\text { or unsure }\end{array}$} & \multicolumn{2}{|c|}{$\begin{array}{c}\text { Unhappy, very } \\
\text { unhappy, or neutra }\end{array}$} \\
\hline & OR & $95 \% \mathrm{Cl}$ & OR & $95 \% \mathrm{Cl}$ & OR & $95 \% \mathrm{Cl}$ & OR & $95 \% \mathrm{Cl}$ & OR & $95 \% \mathrm{Cl}$ & OR & $95 \% \mathrm{Cl}$ \\
\hline \multicolumn{13}{|l|}{ Tobacco } \\
\hline Never & Ref & & Ref & & Ref & & Ref & & Ref & & Ref & \\
\hline Once/twice or monthly & 1.85 & $0.26-13.09$ & 1.77 & $0.30-10.51$ & 0.90 & $0.14-5.88$ & 2.37 & $0.39-14.4$ & 2.31 & $0.32-16.72$ & 2.85 & $0.30-27.01$ \\
\hline Weekly or daily & 2.17 & $0.63-7.48$ & 0.72 & $0.24-2.19$ & 0.94 & $0.30-2.93$ & 1.83 & $0.68-4.98$ & 4.00 & $1.14-14.06$ & 7.56 & $1.65-34.51$ \\
\hline \multicolumn{13}{|c|}{ 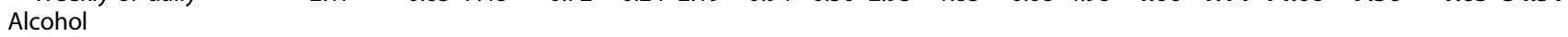 } \\
\hline Never & Ref & & Ref & & Ref & & Ref & & Ref & & Ref & \\
\hline Once/twice or monthly & 3.29 & $1.08-10.08$ & 2.81 & $1.07-7.36$ & 2.15 & $0.80-5.79$ & 1.71 & $0.67-4.36$ & 0.52 & $0.13-2.12$ & 0.16 & $0.03-0.76$ \\
\hline Weekly or daily & 0.68 & $0.13-3.50$ & 1.20 & $0.33-4.35$ & 1.24 & $0.31-5.02$ & 0.57 & $0.14-2.30$ & 0.69 & $0.09-5.45$ & 1.33 & $0.21-8.36$ \\
\hline \multicolumn{13}{|c|}{ (1. } \\
\hline None & Ref & & Ref & & Ref & & Ref & & Ref & & Ref & \\
\hline Once/twice or monthly & 1.99 & $0.35-11.35$ & 2.06 & $0.49-8.73$ & 1.33 & $0.31-5.71$ & 2.23 & $0.52-9.60$ & 1.38 & $0.29-6.56$ & 3.45 & $0.65-18.20$ \\
\hline Weekly or daily & 1.42 & $0.27-7.41$ & 1.96 & $0.45-8.54$ & 1.66 & $0.39-6.97$ & 1.53 & $0.40-5.78$ & 1.69 & $0.33-8.72$ & 3.26 & $0.47-22.66$ \\
\hline \multicolumn{13}{|c|}{ מ } \\
\hline None & Ref & & Ref & & Ref & & Ref & & Ref & & Ref & \\
\hline Tobacco only & 0.20 & $0.02-1.84$ & 0.10 & $0.01-1.21$ & 0.18 & $0.02-1.62$ & 0.24 & $0.02-2.80$ & 0.23 & $0.01-5.33$ & 0.82 & $0.06-11.33$ \\
\hline Alcohol only & 0.86 & $0.26-2.93$ & 1.33 & $0.42-4.23$ & 1.04 & $0.30-3.61$ & 0.59 & $0.20-1.78$ & 0.09 & $0.01-0.55$ & 0.07 & $0.01-0.48$ \\
\hline Tobacco and alcohol & 3.50 & $0.84-14.59$ & 1.92 & $0.54-6.86$ & 1.61 & $0.43-6.01$ & 2.19 & $0.72-6.61$ & 2.41 & $0.62-9.28$ & 2.91 & $0.75-11.26$ \\
\hline \multicolumn{13}{|c|}{ 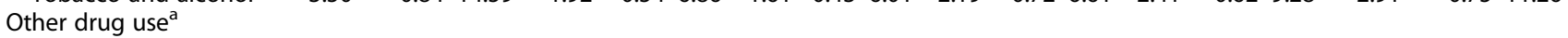 } \\
\hline No & Ref & & Ref & & Ref & & Ref & & Ref & & Ref & \\
\hline Yes & NAC & & 6.91 & $0.83-57.33$ & NAC & & NAC & & 1.30 & $0.27-6.30$ & 0.18 & $0.03-1.00$ \\
\hline
\end{tabular}

Bold text indicates a statistical significance with a $p$-value of $<0.05$; Variables including employment, age, gestational age, education, marital status, race/ethnicity, parity, chronic medical problem, language, previous abortion, previous miscarriage, history of depression, history of anxiety, other substance use in addition to exposure of interest, and recruitment site evaluated as potential confounders in multivariable modeling using backwards selection.

${ }^{\mathrm{a}}$ Defined as use of stimulants, inhalants, sedatives, cocaine, and opioids.

NAC, not able to calculate. 
unhappiness with pregnancy news among women smoking tobacco during the periconceptional period.

Our robust analysis of multiple periconception substances and unique measures of pregnancy context in early pregnancy improves upon the current literature and illustrates the complexity of these relationships, which has important public health implications. For example, despite frequent public health focus on unintended pregnancy and substance use, ${ }^{9-11}$ we demonstrate substance use was also associated with unwanted, undesired, and unhappy pregnancies. Public health efforts focused solely on pregnancy intention would potentially miss these other important pregnancy contexts, especially pregnancy contexts that reflect women's perspectives about the pregnancy after its diagnosis (desirability and happiness).

Our study improves upon earlier studies that are limited by potential misclassification of pregnancy intention based on complicated algorithms, ${ }^{13,16}$ utilize national surveys $^{11,13,16}$ with retrospective assessments of pregnancy context and substance exposure that may be subject to recall bias, ${ }^{11,14,15,26}$ and lack robust adjustment for potential confounders. ${ }^{10}$ In addition, our study is strengthened by enrolling women early in gestation; assessing substance exposure during the 3 months before enrollment (prospective to pregnancy outcome); directly assessing unique pregnancy contexts beyond intention, thus minimizing potential recall bias; and adjustment for multiple covariates in statistical analysis.

After adjustment for potential confounders including history of depression and/or anxiety, most significant substance use risk estimates were attenuated, demonstrating the importance of comprehensive multivariable modeling that includes evaluating history of depression and/or anxiety. Finally, we recruited women presenting for pregnancy testing, inclusive of all pregnancy outcomes including induced abortion, thus enhancing generalizability of our findings compared with studies frequently restricted to live births only. ${ }^{11,13,16,26}$

Another strength of our study is its potential external generalizability. Our cohort is diverse in participant characteristics including race-ethnicity, marital status, education, and language. Research among a sociodemographically diverse population provides opportunities to better understand potential health disparities.

Periconceptional substance use in this study is similar to or above national estimates. ${ }^{29}$ Specifically, reported alcohol use (54\%) is consistent with previous research among reproductive aged women, ${ }^{21,22,29}$ whereas tobacco and marijuana use in our study ( $31 \%$ and $21 \%$, re- spectively) are above estimates among U.S. reproductiveaged women, ${ }^{21}$ suggesting reporting bias may be minimal. Notably, marijuana use is within estimates of use among younger urban populations $(15 \%-28 \%){ }^{30}$ Illicit substance use in our study, including marijuana (21\%), cocaine $(<1 \%)$, inhalants $(<1 \%)$, and opioids $(1.6 \%)$, is collectively higher $(22.8 \%)$ than composite illicit drug use among pregnant (5.4\%) and nonpregnant (11.4\%) U.S. women of age $15-44$ years, ${ }^{29}$ and greater than previously reported periconceptional illicit substance use. ${ }^{31}$

Several study limitations are important to acknowledge. We did not assess income or recent contraception use, which may be important potential confounders. Our relatively small sample limits further stratification of substance exposure, and we are limited in our assessment of high levels of substance exposure. Specific substance measures, such as alcohol frequency, are limited in that they may not fully capture the scope of substance use and behavior. Further research delineating patterns of substance use (e.g., binge drinking) and higher sustained levels of substance use (e.g., chronic heavy drinking) and unfavorable pregnancy contexts would be informative.

In addition, few women in our study report using other illicit substances, including opioids; these substances are analyzed as a composite measure, precluding evaluation of individual illicit substances, or differentiation between illicit versus medically prescribed substances. Although self-reported substance use is subject to recall and social desirability bias, periconceptional exposure is assessed early in pregnancy among women averaging 7.5 weeks' gestation (range 3.7-18.7 weeks). Although exposure during the "past 3 months" may vary and encompass pre- and postconceptional period for most participants, methodological consistency was applied assessing exposure within 3 months before enrollment and pregnancy diagnosis, thus minimizing bias.

Further research is warranted identifying detailed substance exposure during the specific immediate preconception period as well as postconception period before pregnancy recognition, compared with after pregnancy recognition when behavior is often modified. Biomarkers of exposure were not collected for our analysis, which would increase precision of exposure assessment. In addition, although underreporting may threaten exposure assessment, acceptable agreement between self-reported substance use and toxicology results has been reported. ${ }^{32}$

Our study demonstrates associations between periconceptional substance exposure and unique measures of pregnancy context among a diverse cohort of pregnant 
women. These findings support the need for more nuanced public health interventions that improve upon overly cautious and potentially impractical advice to all reproductive-aged women to avoid substances in case they get pregnant. ${ }^{33,34}$ Instead, public health efforts that support women's "reproductive life planning" and encourage patient-centered assessments ${ }^{6}$ regarding potential pregnancy contexts, identify those at risk of unfavorable pregnancy contexts (e.g., unintended, unwanted, and undesired), and facilitate contraceptive access for those who want to avoid pregnancy may be more beneficial.

More specifically, our finding that periconceptional alcohol use was associated with increased odds of unintended or ambivalent pregnancy and unwanted or mixed feelings regarding pregnancy provides potential opportunities for decreasing negative birth outcomes associated with alcohol-exposed pregnancies. Furthermore, enhancement of preconception education and delivery of evidence-based information are needed, along with interventions to optimize preconception health. ${ }^{35}$

Specific interventions to address preconceptional alcohol and tobacco use and effective contraception for those at risk of unintended pregnancy have been demonstrat$\mathrm{ed}^{24}$ and may be an important step to address the increased risk of unfavorable pregnancy context measures we observe among women with periconceptional substance use. For example, the CHOICES Plus trial demonstrated a preconception intervention reduced the risk of alcohol- and tobacco-exposed pregnancies within primary health care settings, ${ }^{24}$ and future efforts integrating similar approaches within reproductive health care and family planning settings should be evaluated.

Notably, our findings also reinforce growing literature that asserts pregnancy planning and intention may not have relevance for some women, ${ }^{5,18}$ and warrant further assessment of improved measures regarding pregnancy contexts, ${ }^{5,17-20}$ including how, when, and where these expanded context measures can be best used in clinical practice.

Our study highlights important pregnancy context measures beyond the construct of intention, and demonstrates opportunities to enhance education regarding contraception, substance use, and preconception health among reproductive-age women, especially those with the potential for unintended, unwanted, undesired, or unhappy pregnancies. These findings underscore the potential for increased contraceptive access as a public health primary prevention strategy for substance use in pregnancy, particularly for women at risk for unfavorable pregnancy contexts.

\section{Author Disclosure Statement}

No competing financial interests exist.

\section{Funding Information}

Dr. Gariepy was supported by funding from NIH CTSA UL1 TR000142 and the Albert McKern Scholar Awards for Perinatal Research, which also supported Dr. Lundsberg, during the conduct of the study. Dr. Gariepy was also supported by NIDA 5K12DA033312.

\section{References}

1. American College of Obstetricians and Gynecologists (ACOG). Prepregnancy counseling. Committee Opinion Number 762. Available at: https:// www.acog.org/-/media/Committee-Opinions/Committee-onGynecologic-Practice/co762.pdf?dmc=1\&ts=20191219T1626155460 viewed in December 18, 2019.

2. Centers for Disease Control and Prevention (CDC). Planning for pregnancy: preconception care 2018. Available at: https://www.cdc.gov/ preconception/planning.html viewed in December 18, 2019.

3. World Health Organization. Preconception care: Maximizing the gains for maternal and child health. Geneva, Switzerland: WHO, 2013.

4. Royal College of Obstetricans and Gyaenecologists (RCOG) Patient Information Committee. Alcohol and Pregnancy. February 2015 (reviewed January 2018). Available at: https://www.rcog.org.uk/ globalassets/documents/patients/patient-information-leaflets/ pregnancy/pi-alcohol-and-pregnancy.pdf viewed in December 18, 2019.

5. Borrero S, Nikolajski C, Steinberg JR, et al. "It just happens": A qualitative study exploring low-income women's perspectives on pregnancy intention and planning. Contraception 2015;91:150-156.

6. Morse JE, Moos M-K. Reproductive life planning: Raising the questions. Matern Child Health J 2018;22:439-444 |

7. Finer LB, Zolna MR. Declines in unintended pregnancy in the United States, 2008-2011. N Engl J Med 2016;374:843-852.

8. Bearak J, Popinchalk A, Alkema L, Sedgh G. Global, regional, and subregional trends in unintended pregnancy and its outcomes from 1990 to 2014: Estimates from a Bayesian hierarchical model. Lancet Global Health 2018;6:PE380-E389.

9. Hellerstedt WL, Pirie PL, Lando HA, et al. Differences in preconceptional and prenatal behaviors in women with intended and unintended pregnancies. Am J Public Health 1998;88:663-666.

10. Heil SH, Jones HE, Arria A, et al. Unintended pregnancy in opioid-abusing women. J Subst Abuse Treat 2011;40:199-202.

11. Naimi TS, Lipscomb LE, Brewer RD, Gilbert BC. Binge drinking in the preconception period and the risk of unintended pregnancy: Implications for women and their children. Pediatrics 2003;111:1136-1141.

12. Lundsberg LS, Peglow S, Qasba N, Yonkers KA, Gariepy AM. Is preconception substance use associated with unplanned or poorly timed pregnancy? J Addict Med 2018;12:321-328.

13. Terplan M, Cheng D, Chisolm MS. The relationship between pregnancy intention and alcohol use behavior: An analysis of PRAMS data. J Subst Abuse Treat 2014;46:506-510.

14. Than LC, Honein MA, Watkins ML, Yoon PW, Daniel KL, Correa A. Intent to become pregnant as a predictor of exposures during pregnancy: Is there a relation? J Reprod Med 2005;50:389-396.

15. Dott M, Rasmussen SA, Hogue CJ, Reefhuis J, National Birth Defects Prevention Study. Association between pregnancy intention and reproductive-health related behaviors before and after pregnancy recognition, National Birth Defects Prevention Study, 1997-2002. Matern Child Health J 2010;14:373-381.

16. Chisolm MS, Cheng D, Terplan M. The relationship between pregnancy intention and change in perinatal cigarette smoking: An analysis of PRAMS data. J Subst Abuse Treat 2014;46:189-193.

17. Santelli JS, Lindberg LD, Orr MG, Finer LB, Speizer I. Toward a multidimensional measure of pregnancy intentions: Evidence from the United States. Stud Fam Plann 2009;40:87-100.

18. Mumford SL, Sapra JK, King RB, Louis JF, Buck Louis GM. Pregnancy intentions-a complex construct and call for new measures. Fertil Steril 2016;106:1453-1462. 
19. Gariepy A, Lundsberg LS, Vilardo N, Stanwood N, Yonkers KA, Schwarz EB. Pregnancy context and women's health-related quality of life. Contraception 2017;95:491-499.

20. Aiken AR, Borrero S, Callegari LS, Dehlendorf C. Rethinking the pregnancy planning paradigm: Unintended conceptions or unrepresentative concepts? Perspect Sex Reprod Health 2016;48:147-151.

21. McHugh RK, Wigderson S, Greenfield SF. Epidemiology of substance use in reproductive-age women. Obstet Gynecol Clin North Am 2014;41:177-189.

22. Slater ME, Haugwout SP, Castle I-JP. Trends in substance use among reproductive-age females in the United States, 2002-2013. National Institute on Alcohol Abuse and Alcoholism. Surveillance report \#103. September 2015. Available at: https://pubs.niaaa.nih.gov/publications/ surveillance103/SUBST01.htm viewed in August 1, 2019.

23. Lundsberg LS, Xu X, Schwarz EB, Gariepy AM. Measuring health utility in varying pregnancy contexts among a diverse cohort of pregnant women. Contraception 2017;96:411-419.

24. Velasquez MM, von Sternberg KL, Floyd RL, et al. Preventing alcohol and tobacco exposed pregnancies: CHOICES Plus in primary care. Am J Prev Med 2017;53:85-95.

25. Barrett G, Smith SC, Wellings K. Conceptualisation, development and evaluation of a measure of unplanned pregnancy. J Epidemiol Community Health 2004;58:426-433.

26. Oulman E, Kim, THM, Yunk K, Tamin H. Prevalence and predictors of unintended pregnancy among women: An analysis of the Canadian Maternity Experiences Survey. BMC Pregnancy Childbirth 2015;15:1-8.

27. Everett BG, McCabe KF, Hughes TL. Unintended pregnancy, depression, and hazardous drinking in a community-based sample of sexual minority women. J Womens Health 2016;25:904-911.

28. Cheng D, Schwarz EB, Douglas E, Horon I. Unintended pregnancy and associated maternal preconception, prenatal and postpartum behaviors. Contraception 2009;79:194-198.

29. Substance Abuse and Mental Health Services Administration (SAMHSA). Results from the 2013 National Survey of Drug Use and Health: Summary of National Findings. NSDUH Series H-48, HHS Publication No. (SMA) 14-4863. Rockville, MD: Substance Abuse and Mental Health Services Administration, 2014. Available at: https://www.samhsa.gov/data/sites/ default/files/NSDUHresultsPDFWHTML2013/Web/NSDUHresults2013.pdf viewed in December 18, 2019.
30. American College of Obstetricians and Gynecologists (ACOG). Marijuana use during pregnancy and lactation Committee Opinion Number 722 October 2017. Available at: https://www.acog.org/-/media/CommitteeOpinions/Committee-on-Obstetric-Practice/co722.pdf?dmc $=1 \&$ ts $=$ 20180627 T1839504682 viewed in August 1, 2019.

31. van Gelder MM, Reefhuis J, Caton AR, et al. Maternal periconceptional illicit drug use and the risk of congenital malformations. Epidemiology 2009;20:60-66.

32. Yonkers KA, Howell HB, Gotman N, Rounsaville BJ. Self-report of illicit substance use versus urine toxicology results from at-risk pregnant women. J Subst Use 2011;16:372-389.

33. Green PP, McKnight-Eily LR, Tan CH, Mejia R, Denny CH. Vital Signs: Alcohol-exposed pregnancies-United States, 2011-2013. MMWR Morb Mortal Wkly Rep 2016;65:91-97.

34. Centers for Disease Control and Prevention (CDC). More than 3 million US women at risk for alcohol-exposed pregnancy: Sexually active women who stop using birth control should stop drinking alcohol, but most keep drinking. February 2, 2016. Available at: https://www.cdc.gov/media/releases/ 2016/p0202-alcohol-exposed-pregnancy.html Accessed October 11, 2018.

35. Hemsing N, Greaves L, Poole N. Preconception health care interventions: A scoping review. Sex Reprod Healthcare 2017;14:24-32.

Cite this article as: Lundsberg LS, Pensak MJ, Gariepy AM (2020) Is periconceptional substance use associated with unintended pregnancy, Women's Health Report 1:1, 17-25, DOI: 10.1089/ whr.2019.0006.

\section{Appendix Table A1}

\section{Appendix Table A1. Measures of Pregnancy Context}

\begin{tabular}{|c|c|c|}
\hline Context & Enrollment question and response & Context measure for analysis \\
\hline \multicolumn{3}{|c|}{ Prepregnancy perspectives of pregnancy: intention, wantedness, planning } \\
\hline \multirow[t]{2}{*}{ Intention ${ }^{a}$} & Just before I became pregnant I intended to get pregnant & Intended \\
\hline & Just before I became pregnant my intentions kept changing/... I did not intend to get pregnant & $\begin{array}{l}\text { Unintended or intentions } \\
\text { changing }\end{array}$ \\
\hline \multirow[t]{2}{*}{ Wanted $^{\mathrm{a}}$} & Just before I became pregnant I wanted to have a baby & Wanted \\
\hline & $\begin{array}{l}\text { Just before I became pregnant I had mixed feelings about having a baby/... I did not want to have } \\
\text { a baby }\end{array}$ & Unwanted or mixed feelings \\
\hline \multirow[t]{2}{*}{ Planning ${ }^{\mathrm{b}}$} & Planned. (scoring 10-12 on LMUP) & Planned \\
\hline & Ambivalent (scoring 4-9 on LMUP) unplanned (scoring $0-3$ on LMUP) & Unplanned or ambivalent \\
\hline \multicolumn{3}{|c|}{ Postconception perspectives of pregnancy: timing, desired, happiness } \\
\hline \multirow[t]{2}{*}{ Timing ${ }^{\mathrm{a}}$} & $\begin{array}{l}\text { In terms of becoming a mother (first time or again), I feel that my pregnancy happened at the } \\
\text { right time }\end{array}$ & Well-timed \\
\hline & $\begin{array}{l}\text { In terms of becoming a mother (first time or again), I feel that my pregnancy happened at the okay } \\
\text { but not quite right time/...my pregnancy happened at the wrong time }\end{array}$ & $\begin{array}{l}\text { Not quite right time } \\
\text { or poorly timed }\end{array}$ \\
\hline \multirow[t]{2}{*}{ Desired } & Is this pregnancy desired?-Yes & Desired \\
\hline & Is this pregnancy desired?-Not sure/ls this pregnancy desired?-No & Undesired or not sure \\
\hline \multirow[t]{2}{*}{ Happiness } & Rate how happy you felt when you found out you were pregnant: Very happy, somewhat happy & Happy \\
\hline & $\begin{array}{l}\text { Rate how happy you felt when you found out you were pregnant: very unhappy, somewhat } \\
\text { unhappy, neutral, do not know }\end{array}$ & Unhappy, neutral \\
\hline
\end{tabular}

Table of context measures adapted from Gariepy et al. ${ }^{19}$ and Lundsberg et al. ${ }^{23}$

a Pregnancy intention, wantedness, and timing based on questions from the LMUP. ${ }^{25}$

bPlanning based on the LMUP. ${ }^{25}$

LMUP, London Measure of Unplanned Pregnancy. 